\title{
Acute Respiratory Distress Syndrome after Rotavirus Infection in a C1q Nephropathy Patient: A Case Report
}

\author{
Hye Jin Kim, M.D. ${ }^{1}$ \\ Jeesu Min, M.D. ${ }^{1}$ \\ Ji Hyun Kim, M.D., M.S. ${ }^{2,5}$ \\ Yu Hyeon Choi, M.D., M.S. ${ }^{3}$ \\ Mi Seon Han, M.D., Ph.D. ${ }^{4}$ \\ II-Soo Ha, M.D., Ph.D. ${ }^{1,5}$ \\ Hee Gyung Kang, M.D., Ph.D. ${ }^{1,5}$

\begin{abstract}
${ }^{1}$ Department of Pediatrics, Seoul National ${ }^{2}$ Department of Pediatrics, Seoul National University Bundang Hospital, Seongnam, Korea, ${ }^{3}$ Department of Pediatrics,Anyang University Seoul Hospital, Seoul, Korea, ${ }^{4}$ Department of Pediatrics, Seoul Metropolitan Government-Seoul National University Boramae Medical Center, Seoul, Korea, ${ }^{5}$ Department of Pediatrics, Seoul National University College of Medicine, Seoul, Korea
\end{abstract} \\ University Children's Hospital, Seoul, Korea,
}

Corresponding author:

Hee Gyung Kang, M.D., Ph.D.

Division of Pediatric Nephrology,

Department of Pediatrics, Seoul National

University Children's Hospital \& Seoul

National University College of Medicine 101

Daehak-ro, Jongno-Gu, Seoul 03080, Korea

Tel: +82-2-2072-0658

Fax: +82-2-743-3455

E-mail:kanghg@snu.ac.kr

Received: 1 September 2021

Revised: 24 October 2021

Accepted: 30 October 2021

This is an open-access article distributed under the terms of the Creative Commons Attribution Non-Commercial License (http:// creativecommons.org/licenses/by-nc/4.0/) which permits unrestricted non-commercial use, distribution, and reproduction in any medium, provided the original work is properly cited.

Copyright (C) 2021 The Korean Society of Pediatric Nephrology
C1q nephropathy is a rare glomerulopathy that typically presents with nephrotic syndrome in children. Treatment with immunosuppressive agents renders patients vulnerable to infection and its complications. Gastroenteritis is common in children, and rotavirus is a leading cause. Extraintestinal manifestations of rotavirus have recently been reported; however, there is a paucity of cases exploring the involvement of a rotavirus on the respiratory system. Acute respiratory distress syndrome (ARDS) is a rapid onset respiratory failure characterized by noncardiogenic pulmonary edema and hypoxemia. Causes of ARDS include sepsis, pneumonia, pancreatitis, aspiration, and trauma. In this paper, we report a case of ARDS after rotavirus infection in a child with C1q nephropathy who had been treated with immunosuppressive agents.

Key words: Acute respiratory distress syndrome, Complement C1q, Glomerulonephritis, Rotavirus infections

\section{Introduction}

Clq nephropathy is a relatively uncommon glomerulopathy that typically presents with nephrotic syndrome in children and young adults. It was first described by Jennett and Hipp in 1985 and was characterized by predominant Clq deposition in the glomerular mesangium ${ }^{1}$. Steroid dependency with frequent relapse is the most frequent outcome, and a second line immunosuppressant is often added in refractory cases. While immunosuppressive agents, including steroids, are the mainstay of treatment for glomerulonephritis, including $\mathrm{Clq}$ nephropathy, immunosuppression renders patients vulnerable to infection and its complications.

Among infectious diseases, gastroenteritis is common in children. Rotaviruses are among the first proven viral agents of the major pathogens that cause acute gastroenteritis in infants and young children. The initial detection of rotavirus was made via duodenal mucosal biopsies of children with gastroenteritis in $1973^{2}$. Since then, the virus was presumed to only affect the intestinal tract. However, evidence of extraintestinal manifestations caused by systemic rotavirus infection has been documented in recent studies. Symptoms include seizure, pneumonia, hepatitis, pancreatitis, and autoimmune diseases ${ }^{3)}$.

Acute Respiratory Distress Syndrome (ARDS) is a condition that presents 
as an acute respiratory failure due to an acute diffuse alveolar injury, resulting in gas exchange impairment. The Pediatric Acute Lung Injury Consensus Conference Group has defined pediatric ARDS as an acute onset hypoxemia (Oxygenation index $\geq 4$ in patients treated with invasive mechanical ventilation) that presents with new pulmonary infiltrate consistent with acute pulmonary parenchymal disease on chest imaging and respiratory failure not fully explained by cardiac failure or fluid overload ${ }^{4)}$. Etiologies of ARDS include pneumonia, sepsis, aspiration, pancreatitis, trauma, and drugs; however, reports on rotavirus infection-associated ARDS are scarce and only deal with isolated cases ${ }^{5,6)}$.

Here, we report a pediatric case of C1q nephropathy treated with immunosuppressive agents in a patient who developed ARDS after a rotavirus infection.

\section{Case report}

An 8-year-old girl was admitted to our hospital for scheduled methylprednisolone pulse therapy to manage her Clq nephropathy. Her proteinuria was initially found when she was admitted for status epilepticus and fever at 5 years of age. At that time, generalized edema developed, along with severe proteinuria and azotemia (urine protein/ creatinine ratio $5.74 \mathrm{mg} / \mathrm{mg}$, serum albumin $3.2 \mathrm{~g} / \mathrm{dL}$, blood urea nitrogen $20 \mathrm{mg} / \mathrm{dL}$, creatinine $0.95 \mathrm{mg} / \mathrm{dL}$ ). However, her proteinuria improved spontaneously. Epilepsy was managed via multiple antiepileptic drugs including valproate, levetiracetam, lamotrigine, and ethosuximide. Two years later, nephrotic range proteinuria recurred with hypoalbuminemia (urine protein/creatinine ratio 8.59 $\mathrm{mg} / \mathrm{mg}$, serum albumin $2.3 \mathrm{~g} / \mathrm{dL}$ ), which did not respond to a steroid treatment. Kidney biopsy revealed glomerulosclerosis (global sclerosis $12.9 \%$, segmental sclerosis $34.1 \%$ ) and dominant positive staining (3+) for Clq in the glomerular mesangium and periphery (Fig. 1). Upon the diagnosis of Clq nephropathy, a management plan involving immunosuppressive agents was initiated. However, her nephropathy was not ameliorated, and her azotemia worsened, despite the use of steroids, azathioprine, and mycophenolate mofetil (MMF). As a last effort to induce the remission of her nephropathy and preserve her kidney function, methylprednisolone pulse therapy was planned.

On the day of admission for methylprednisolone, she complained of vomiting, diarrhea, and abdominal pain that started the day prior. She was on MMF and enalapril at the time of admission. Her blood pressure was 116/78 $\mathrm{mmHg}$, her pulse rate was $99 / \mathrm{min}$, and her body temperature was $36.4^{\circ} \mathrm{C}$. Laboratory findings were as follows: serum albumin level $2.4 \mathrm{~g} / \mathrm{dL}$, blood urea nitrogen (BUN) $34 \mathrm{mg} /$ $\mathrm{dL}$, creatinine (Cr) $1.56 \mathrm{mg} / \mathrm{dL}$, and Schwartz estimated glomerular filtration rate (eGFR) $27.4 \mathrm{~mL} / \mathrm{min} / 1.73 \mathrm{~m}^{2}$. She had proteinuria (urine protein-creatinine ratio 9.28 $\mathrm{mg} / \mathrm{mg}$ ) without hematuria. Under the impression of hypovolemic crisis, albumin was administered, followed by a high dose of a steroid as planned. However, the steroid was discontinued after the patient developed a fever. Only 30 mg of methylprednisolone, which was $5 \%$ of the scheduled amount, was infused. MMF was also discontinued due to the fever. On the following day, she complained of sudden dyspnea. Her respiration rate was $40 / \mathrm{min}$, and her saturation of percutaneous oxygen $\left(\mathrm{SpO}_{2}\right)$ was $91 \%$ at room air conditions. Her respiration rapidly deteriorated, and the administration of supplemental oxygen $(5 \mathrm{~L} / \mathrm{min})$ via a

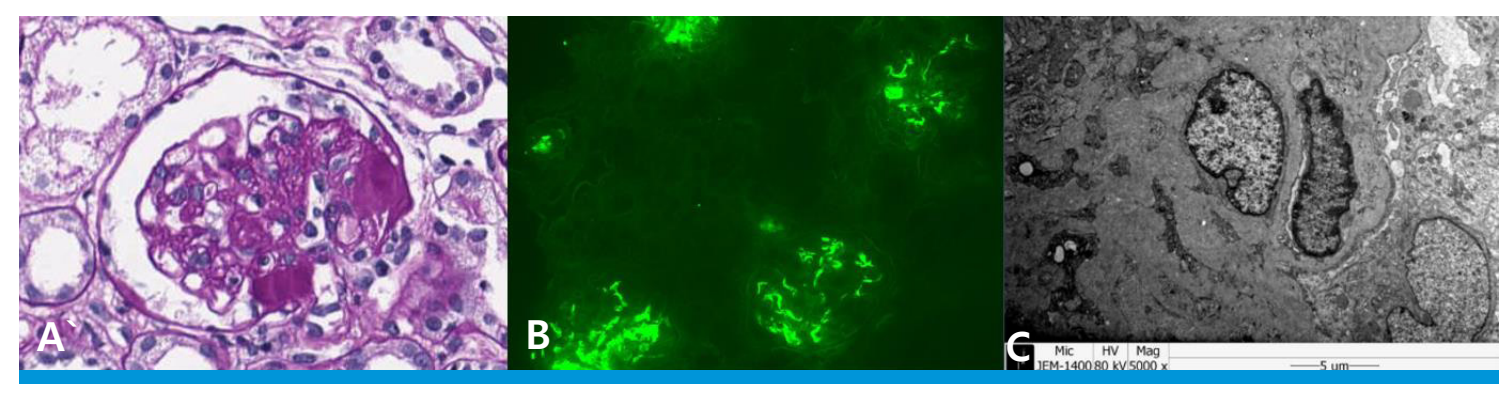

Fig. 1. Kidney biopsy findings of the patient. (A) Light microscopy examination (Periodic acid-Schiff stain, x400) showed segmental glomerulosclerosis. (B) Immunofluorescence microscopy (x200) revealed dominant staining (3+) for C1q in the mesangium and periphery. (C) Electron microscopy showed electron-dense deposits in the mesangium and subendothelium. 
facial mask was required to maintain $\mathrm{SpO}_{2}>95 \%$ over an eight-hour period. Chest X-ray (Fig. 2) and computed tomography (CT) images (Fig. 3) revealed rapidly progressive bilateral pulmonary consolidation. Her urine output decreased to $0.68 \mathrm{~mL} / \mathrm{kg} / \mathrm{h}$, and her azotemia had progressed (BUN 40 mg/dL, Cr 2.12 mg/dL). Acute kidney injury (AKI) could have been caused by dehydration from vomiting and diarrhea (approximately ten times a day). Urinalysis and kidney sonography were performed for further investigations; they showed no evidence of renal calculi, which could have caused post-renal failure. As her dyspnea aggravated with the deterioration of kidney function, we suspected AKI-induced pulmonary edema. However, her need for oxygen increased even after emergency hemodialysis. At that time, her stool exam returned positive for rotavirus antigen; moreover, she had not received the rotavirus vaccine.

On the third day of admission, she had a generalized tonic-clonic seizure, and acute respiratory failure, which had progressed within 24 hours from the onset of the symptoms of rotavirus infection. Both chest X-ray and CT images showed new onset pulmonary infiltrations not fully explained by effusions, collapsed lung, or nodules. Echocardiography showed no evidence of cardiac failure. Lastly, the patient's oxygenation index was 16.2, indicative of severe ARDS. Upon the diagnosis of ARDS, she was transferred to an intensive care unit (ICU) and started mechanical ventilator care. In addition, continuous renal replacement therapy (CRRT) was applied for the treatment of AKI. Due to her immunocompromised condition, intravenous trimethoprim-sulfamethoxazole, piperacillin/tazobactam, and ganciclovir were empirically administered for atypical pneumonia. Despite thorough investigations to find the causative pathogen of respiratory failure, including a bronchoalveolar lavage (BAL) examination and serologic testing, no clinically significant positive findings

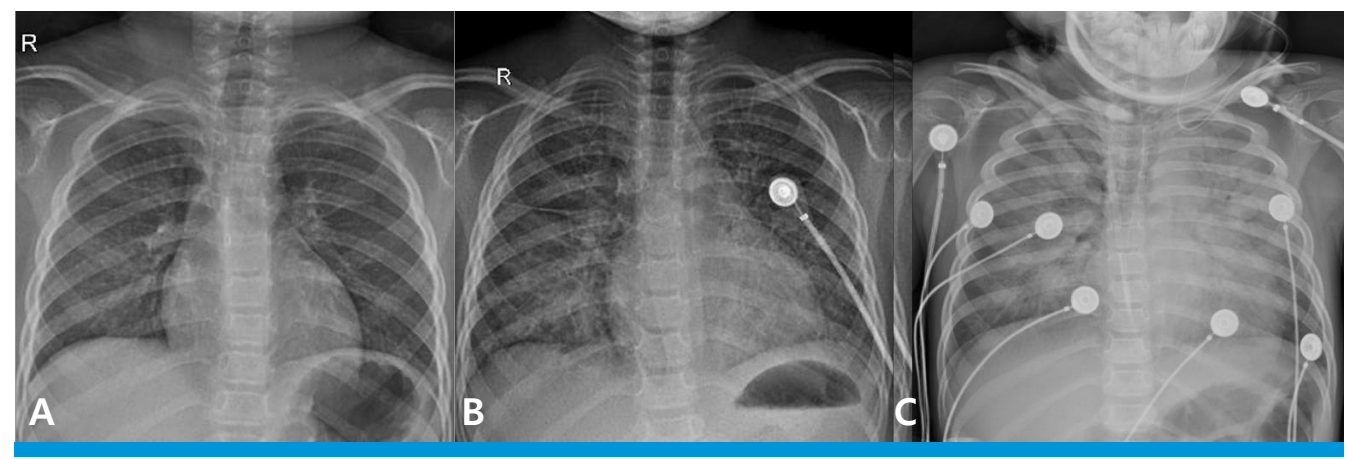

Fig. 2. Radiographic findings. (A) Chest X-ray on admission showed no remarkable findings. (B) Chest X-ray taken 24 hours post-admission revealed rapidly progressive bilateral consolidation. (C) Chest X-ray on ICU admission showed increased pulmonary infiltrations and bilateral pleural effusion.
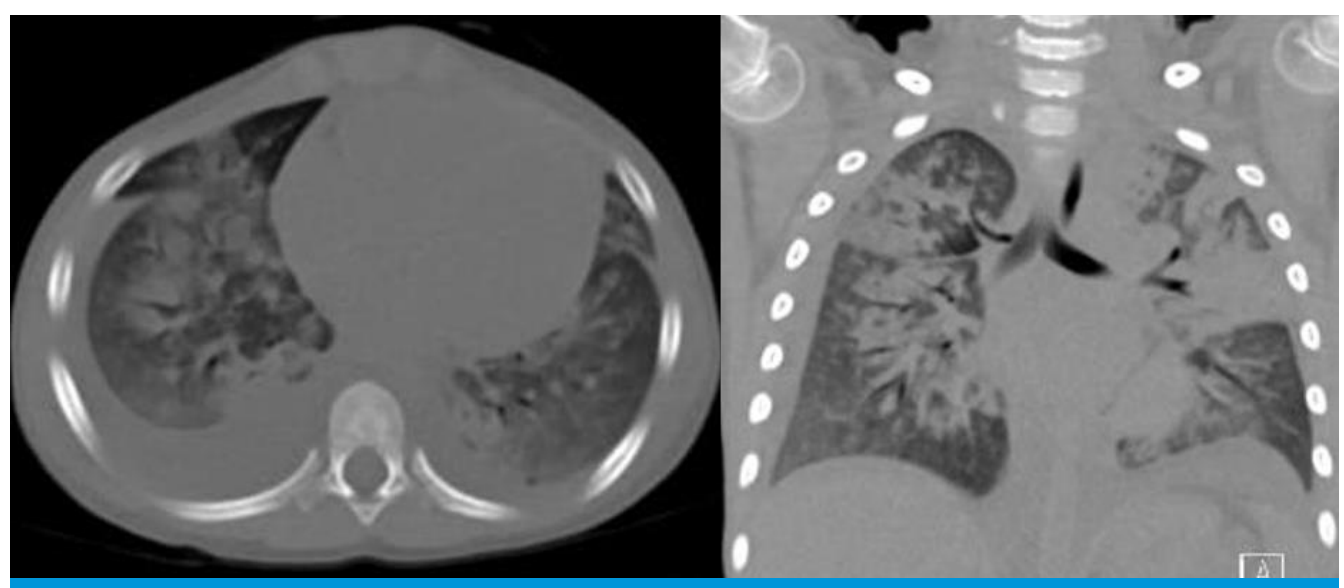

Fig. 3. Chest CT showing bilateral symmetric consolidation and ground glass opacity with bilateral pleural effusion (right>left). 
were discovered in specimen cultures, virus polymerase chain reaction tests.

Her respiratory failure recovered after 7 days of mechanical ventilation. Urination returned after 21 days, over which CRRT was maintained. She was transferred to a general ward after 22 days of ICU care, and she was discharged after the resolution of her ARDS on her 42nd hospitalized day (Fig. 4). At the time of discharge, she had a restored urine output $(1.8 \mathrm{~mL} / \mathrm{kg} / \mathrm{h})$, but she continued to have sig. nificant proteinuria (urine protein/creatinine ratio 26.86 $\mathrm{mg} / \mathrm{mg}$, serum albumin $2.8 \mathrm{~g} / \mathrm{dL}$ ) and stage 4 chronic kidney disease (BUN $38 \mathrm{mg} / \mathrm{dL}$, Cr $1.95 \mathrm{mg} / \mathrm{dL}$, eGFR 22.03 $\mathrm{mL} / \mathrm{min} / 1.73 \mathrm{~m}^{2}$ ).

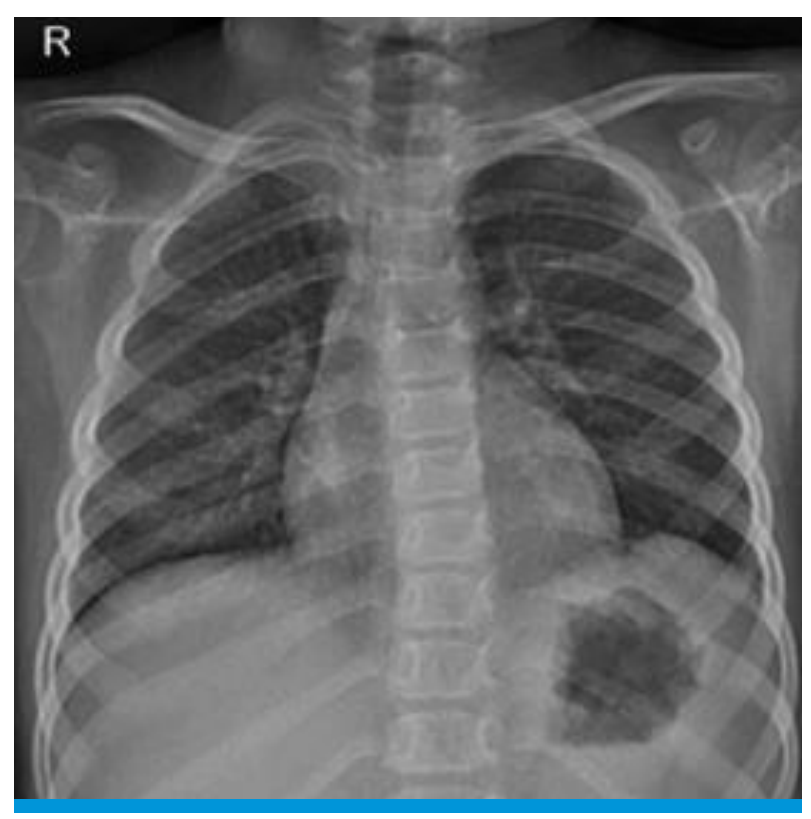

Fig. 4. Chest X-ray on discharge showing resolution of previous lung lesion.

\section{Discussion}

This is a case of ARDS in an immunocompromised patient owing to Clq glomerulopathy. Extensive investigation to identify the causative agents was performed; however, no noteworthy organism was found, other than rotavirus in a stool specimen. Therefore, rotavirus infection was suspected as the most probable culprit associated with ARDS in this case, considering the clinical correspondence and absence of other suspected pathogens.

The spectrum of extraintestinal complications of a rotavirus infection is expanding. Recent studies suggest that a systemic manifestation of rotavirus infection is via vire$\mathrm{mia}^{7}$. Some case reports have detected rotavirus in extraintestinal sites, such as the liver and kidneys, in infected children with immunodeficiencies ${ }^{8)}$.In a retrospective study by Maureen et al., a rotavirus genome was found in the extraintestinal tissues of two out of three children who died after a rotavirus infection. Affected tissues other than the intestine included the spleen, heart, lung, kidney, bladder, testes, adrenal gland, and pancreas ${ }^{3}$. These studies indicate the possibility of rotavirus dissemination through viremia to various extraintestinal sites, resulting in systemic symptoms. The possibility of direct pulmonary infection and viremia of rotavirus could be considered in our case, as well. However, rotavirus was not detected in our patient's BAL fluid, and a serology test for rotavirus antigen was not performed.

While seizure and neurological symptoms are known as the rather common extraintestinal symptoms of rotavirus infection, few case reports have shown impacts of a rotavirus on the respiratory system. Six previous studies on

Table 1. Review of Literature on Respiratory Involvement of Rotavirus

\begin{tabular}{|c|c|c|c|c|c|c|c|}
\hline \multirow{2}{*}{ Reference } & \multirow{2}{*}{ Pts in study, characteristics } & \multirow{2}{*}{ Age range } & \multirow{2}{*}{ Pts of interest* } & \multirow{2}{*}{ Respiratory manifestations } & \multicolumn{3}{|c|}{ Location of RV Ag detection } \\
\hline & & & & & $S$ & $\mathrm{~T}$ & NP \\
\hline Tai et al. (2012) & 100, positive RV Ag & $2-30 d$ & 3 & ARDS & + & & \\
\hline Sasek et al. (2005) & 1 , with gastroenteritis & $8 \mathrm{~m}$ & 1 & ARDS & + & & \\
\hline Zhaori et al. (1991) & 58, with pneumonia & $\leq 4 \mathrm{yrs}$ & 16 & Pneumonia & & + & \\
\hline Santosham et al. (1983) & 45 , with pneumonia & $<5$ yrs & 4 & Pneumonia & + & + & + \\
\hline \multirow[t]{2}{*}{ Lewis et al. (1979) } & 74, positive RV Ag & $8 d-13$ yrs & 49 & Any resp sx & + & & \\
\hline & & & 5 & Pneumonia & + & & \\
\hline Goldwater et al. (1979) & 24 , with gastroenteritis & $<3 y r s$ & 10 & URI sx & + & & \\
\hline
\end{tabular}

*Refers to patients who are positive for rotavirus antigen and have respiratory manifestations.

Abbreviations: Pts, patients; RV, rotavirus; Ag, antigen; S, stool; T, tracheal aspirate; NP, nasopharyngeal aspirate; d, days; m, months; yrs, years; ARDS, acute respiratory distress syndrome; Resp sX, respiratory symptom; URI sX, upper respiratory infection symptom. 
rotavirus involvement in the respiratory system, including ARDS, are summarized in Table $1^{5,6,9-12)}$. Four patients from two papers, with positive rotavirus antigen as indicated by their stool specimens, presented ARDS as in our patients. All of these patients were aged less than one year, and there were no cases among older children. Other studies have demonstrated the presence of rotavirus in respiratory tract secretions in children diagnosed with pneumonia. Some patients with rotavirus infection report milder respiratory symptoms, such as cough and coryza.

Although rotavirus infections are largely self-limited and nearly all children in the world get infected with rotavirus by the age of five, our patient presented severe extraintestinal symptoms at the age of 8 years. Immunodepression may have contributed to extraintestinal rotavirus infection and more severe symptoms. In fact, the bloodstream is considered to be a channel of extraintestinal involvement and is mostly seen in immunocompetent children. Rotavirus antigenemia was initially documented in three immunocompromised patients with chronic rotavirus infection $^{13)}$. Blutt et al. also detected rotavirus antigen and RNA in the sera of immunodeficient patients ${ }^{14)}$. Moreover, it has been observed in previous studies that symptoms are more severe in children with an immature immune system. Although the exact mechanism remains to be determined, $\mathrm{T}$ cells seem to play a crucial role in recurrent rotavirus infection as well as extraintestinal infection. T cell-mediated immune response is one of the main processes involved in the clearance of rotavirus. Additionally, Gilger et al. reported four cases of systemic spread of rotavirus in children with defective T cell responses ${ }^{8}$. Our patient was on MMF, which inhibits $\mathrm{T}$ cell proliferation and adhesion. This could possibly cause recurrent rotavirus infection and also extension beyond the intestinal tract. However, evaluation for $\mathrm{T}$ cell function was not performed in our case and manifestations of $\mathrm{T}$ cell dysfunction, other than severe rotaviral infections, had not been observed.

The case of ARDS with our patient, on the other hand, might have developed due to other causes than infection, such as AKI or chronic kidney disease. Nevertheless, as her respiratory symptoms aggravated despite hemodialysis, it was determined that AKI was not likely to be a contributing factor for ARDS in this case. Furthermore, certain drugs also can cause ARDS. Previously reported causative agents of drug-associated ARDS include chemotherapeutic agents, such as gemcitabine, cyclophosphamide, and methotrexate, as well as antiarrhythmic drugs, such as amiodarone $^{15)}$. There are, however, no reports of ARDS for the drugs our patient was taking: MMF, enalapril, and antiepileptic agents, such as levetiracetam and valproate. In addition, previous studies have shown that drug-induced ARDS tends to resolve shortly after cessation of drug administration. In our case, MMF was discontinued a day before she developed respiratory failure, and even though she continued to take enalapril and antiepileptic drugs, her respiratory symptoms did not aggravate. Thus, these medications are unlikely to be the cause of ARDS in this patient.

In conclusion, our report is noteworthy, given the possibility of rotavirus infection-associated ARDS in an immunocompromised patient. Findings regarding systemic symptoms after a rotavirus infection are broadening, but ARDS following a rotavirus infection is rarely reported. However, the onset time of ARDS after the rotavirus infection was $<24$ hours in this case, and the clinical symptoms observed were correlated with a rotavirus infection. Furthermore, other risk factors of ARDS were excluded. Taken together, these findings suggest that ARDS in our patient was most likely caused by a rotavirus infection. As shown in this case, rotavirus infection or the inflammatory response triggered by it might lead to severe complications such as ARDS, especially in immunocompromised individuals. Therefore, caution should be exercised when managing common infections in patients being treated with immunosuppressive agents.

\section{Acknowledgments}

Patient consent: This study was approved by the institutional review board (IRB), and consent was obtained from the patient and her parent (IRB number H-2107-175-1236).

\section{Funding}

This research did not receive any specific grant from funding agencies in the public, commercial, or not-forprofit sectors. 


\section{Conflicts of interest}

No potential conflict of interest relevant to this article was reported.

\section{ORCID}

Hye Jin Kim https://orcid.org/0000-0001-9111-5572

Jeesu Min https://orcid.org/0000-0003-1535-7769

Ji Hyun Kim https://orcid.org/0000-0001-8477-0157

Yu Hyeon Choi https://orcid.org/0000-0002-3057-0886

Mi Seon Han https://orcid.org/0000-0002-3896-1400

Il-Soo Ha https://orcid.org/0000-0001-5428-6209

Hee Gyung Kang https://orcid.org/0000-0001-8323-5320

\section{References}

1. Jennette JC, Hipp CG. Clq nephropathy: a distinct pathologic entity usually causing nephrotic syndrome. Am J Kidney Dis 1985;6:103-10.

2. Bishop RF, Davidson GP, Holmes H, Ruck BJ. Virus particles in epithelial cells of duodenal mucosa from children with acute non-bacterial gastroenteritis. Lancet 1973;2:1281-3.

3. Lynch M, Shieh WJ, Tatti K, Gentsch JR, Harris TF, Jiang B, et al. The Pathology of Rotavirus-Associated Deaths, Using New Molecular Diagnostics. Clinical Infectious Diseases 2003;37:1327-33.

4. Group PALICC. Pediatric acute respiratory distress syndrome: consensus recommendations from the Pediatric Acute Lung Injury Consensus Conference. Pediatric Critical Care Medicine.
2015;16:428-39.

5. Tai IC, Huang YC, Lien RI, Huang CG, Tsao KC, Lin TY. Clinical manifestations of a cluster of rotavirus infection in young infants hospitalized in neonatal care units. Journal of Microbiology, Immunology and Infection 2012;45:15-21.

6. Sasek L, Pazdiora P, Kobr J, Pizingerová K. Lethal course of rotavirus gastroenteritis-a case history. Klinicka Mikrobiologie a Infekcni Lekarstvi 2005;11:67-9.

7. Blutt SE, Matson DO, Crawford SE, Staat MA, Azimi P, Bennett BL, et al. Rotavirus Antigenemia in Children Is Associated with Viremia. PLOS Medicine 2007;4:e121.

8. Gilger MA, Matson DO, Conner ME, Rosenblatt HM, Finegold MJ, Estes MK. Extraintestinal rotavirus infections in children with immunodeficiency. J Pediatr 1992;120:912-7.

9. Zhaori G, Fu L, Xu Y, Guo Y, Peng Z, Shan W. Detection of rotavirus antigen in tracheal aspirates of infants and children with pneumonia. Chinese Medical Journal 1991;104:830-3.

10. Santosham M, Yolken RH, Quiroz E, Dillman L, Oro G, Reeves WC, et al. Detection of rotavirus in respiratory secretions of children with pneumonia. The Journal of Pediatrics 1983;103:583-5.

11. Lewis HM, Parry JV, Davies HA, Parry RP, Mott A, Dourmashkin RR, et al. A year's experience of the rotavirus syndrome and its association with respiratory illness. Arch Dis Child 1979;54:33946.

12. Goldwater PN, Chrystie IL, Banatvala J. Rotaviruses and the respiratory tract. British Medical Journal 1979;2:1551.

13. Saulsbury FT, Winkelstein JA, Yolken RH. Chronic rotavirus infection in immunodeficiency. The Journal of Pediatrics 1980;97:615.

14. Blutt SE, Kirkwood CD, Parreño V, Warfield KL, Ciarlet M, Estes MK, et al. Rotavirus antigenaemia and viraemia: a common event? The lancet 2003;362:1445-9.

15. Dhokarh R, Li G, SchmickI CN, Kashyap R, Assudani J, Limper AH, et al. Drug-associated acute lung injury: a population-based cohort study. Chest 2012;142:845-50. 